University of Massachusetts Amherst

ScholarWorks@UMass Amherst

National Center for Digital Government

Centers and Institutes

$10-3-2007$

\title{
Reflections of an Online Geographic Information Systems Course Based on Open Source Software
}

Charles M. Schweik

University of Massachusetts Amherst, cschweik@pubpol.umass.edu

Maria Fernandez

University of Massachusetts Amherst

Michael P. Hamel

University of Massachusetts Amherst

Prakash Kashwan

Indiana University

Quentin Lewis

University of Massachusetts Amherst

See next page for additional authors

Follow this and additional works at: https://scholarworks.umass.edu/ncdg

Part of the Computer Sciences Commons, Political Science Commons, and the Science and Technology Studies Commons

Schweik, Charles M.; Fernandez, Maria; Hamel, Michael P.; Kashwan, Prakash; Lewis, Quentin; and Stepanov, Alexander, "Reflections of an Online Geographic Information Systems Course Based on Open Source Software" (2007). National Center for Digital Government Working Paper Series. 13.

Retrieved from https://scholarworks.umass.edu/ncdg/13

This Research, creative, or professional activities is brought to you for free and open access by the Centers and Institutes at ScholarWorks@UMass Amherst. It has been accepted for inclusion in National Center for Digital Government by an authorized administrator of ScholarWorks@UMass Amherst. For more information, please contact scholarworks@library.umass.edu. 
Authors

Charles M. Schweik, Maria Fernandez, Michael P. Hamel, Prakash Kashwan, Quentin Lewis, and Alexander Stepanov

This research, creative, or professional activities is available at ScholarWorks@UMass Amherst: https://scholarworks.umass.edu/ 


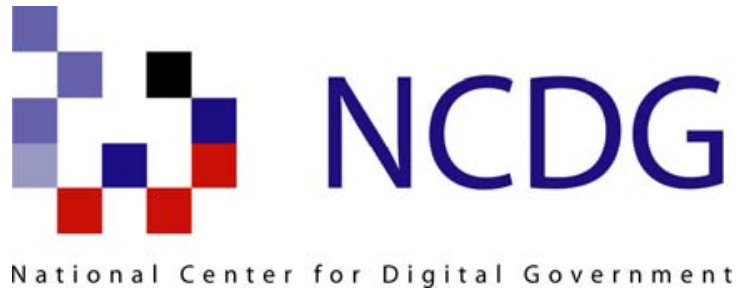

\title{
Reflections of an Online Geographic Information Systems Course Based on Open Source Software
}

\author{
Charles M. Schweik \\ Maria Fernandez \\ Michael P. Hamel \\ Prakash Kashwan \\ Quentin Lewis \\ Alexander Stepanov
}

NCDG Working Paper No. 07-008

Submitted October 3, 2007

This material is based upon work supported by the National Science Foundation under Grant No. 0131923. Any opinions, findings, conclusions, or recommendations expressed in this material are those of the author and do not necessarily reflect the views of the National Science Foundation.

This material has been submitted to Social Science Computer Review, Reports Section and was presented at FOSS4Geo 2007, Victoria, Canada, Sept 24-27 2007 


\title{
REFLECTIONS OF AN ONLINE GEOGRAPHIC INFORMATION SYSTEMS COURSE BASED ON OPEN SOURCE SOFTWARE
}

\author{
Charles M. Schweik*1 \\ Maria Fernandez* \\ Michael P. Hamel* \\ Prakash Kashwan† \\ Quentin Lewis* \\ Alexander Stepanov* \\ * University of Massachusetts, Amherst \\ †Indiana University \\ ${ }^{1}$ Corresponding author. Email address - \\ cschweik@pubpol.umass.edu
}

\begin{abstract}
This SSCORE report summarizes our experience offering an online introductory course on Geographic Information Systems that utilizes available free/libre and open source software (FOSS). Two primary objectives were to (1) reach students in developing countries, and (2) to help move forward the development of an "open content" GIS curriculum as part of the "Open Source Geospatial Foundation” (OSGeo.org) educational effort. Course design, key software (QGIS, GRASS, PostGresql/PostGIS) and online delivery methods are described. Results and factors leading to a low course completion rate and discussed. Contributing factors include: (1) a for-credit versus no-credit decision; and (2) technical issues. Recommendations for others considering online offerings and for the OSGeo educational effort are provided.

Keywords: Geographic information systems, GIS, online instruction, open source software, QGIS, Open Source Geospatial Foundation

Author's note: We are working on a final location for the tutorials we reference in this document which will be somehow linked to the http://www.osgeo.org/education website. For now, the reviewer(s) are welcome to visit our current wiki site: http://inuxlab.sbs.umass.edu/intro-fossgis-umass/

This is currently password protected, but that will change. Userid: foss Password: umass. The final paper (if accepted) will have correct URLs to these tutorials.
\end{abstract}




\section{INTRODUCTION}

Recently there has been rapid development in two areas: (1) online instruction and (2) free/libre and open source software (FOSS) development. In this article we reflect on our recent efforts to combine these phenomena and offer a semester-long online "Introduction to Geographic Information Systems using FOSS” course. Software we utilize are: QGIS (qgis.org), PostgreSQL (postgresql.org/), PostGIS (http://postgis.refractions.net/), and a QGIS plug-in to “GRASS” (http://grass.itc.it/).

We had two objectives for offering such a course, but promoting FOSS as a preferable option over proprietary products was NOT one of them. ${ }^{1}$ Our first objective was to offer an online course that could reach students in developing countries where expense is a barrier to participation. In the age of online instruction, being able to ask students to download free (as in cost) software reduces their course-related expenses. Our second objective was to contribute educational content to the “Open Source Geospatial Foundation” (OSGeo.org) and give back to the community that created the software. Within OSGeo is an education subcommittee working to build GIS educational material. In a complementary research effort, the lead author is studying FOSS development collaboration to investigate what can borrowed and applied to more generic “open content” collaborations (Schweik and English, 2007; Schweik, Evans and Grove, 2005). Our participation in OSGeo's education initiative provides an opportunity to learn about possibilities and challenges in such collaborative efforts.

\section{COURSE DESIGN AND KEY SOFTWARE}

Our course content was based on the logic and structure that the lead author has developed over the course of eight years in teaching GIS using proprietary products. The course assumes no

1 In our view, the question is not whether to use one or the other, but which product adequately fills the particular needs of users. For readers unfamiliar with Geographic Information Systems software, there are a variety of excellent commercial products. ESRI's ArcGIS desktop and enterprise-level product is a leader in this domain. And there are others that have significant functionality and are relatively low-cost in an attempt to reach users who cannot afford higher-end products. Idrissi (http://www.clarklabs.org/) a leader in this segment of the GIS industry. 
prerequisites, other than computer familiarity. One objection the lead author has had with many available GIS texts is that they do not seem to clearly lay out the general sequence found in most GIS projects. The structure, presented in Table 1, is our effort to present such a logic.

After conducting a fairly extensive review of available FOSS GIS software in 2006, we selected the desktop QGIS package (Version 0.8, available at http://www.qgis.org), for it provides much of the functionality we needed for our instructional goals. Extracting from the QGIS overview brochure (http://qgis.org/brochure/qgis_brochure_en.pdf), main functionality includes: (1) the ability to view both raster and vector data and utilize data available in defacto standard formats (Vector: ESRI shapefiles, GRASS vector format; Raster: TIFF, JPG, ArcInfo grids , GRASS raster formats, and Digital Elevation Models or DEMs); (2) compatibility and integration with the more sophisticated and rich functionality found in the GRASS GIS system (http://grass.itc.it); (3) digitizing functions; (4) map composition tools; (5) georeferencing support and (6) general database capabilities, including selecting geographic features and the ability to view feature attributes. Much of the course Introduction (Part I, Table 1) and “GIS Input Methods” (Part II, Table 1) focused on these components of QGIS.

Part II of the course introduces students to the concept of relational databases and Structured Query Language (SQL) to query data, and the joining of spatial and non-spatial data and report creation using attribute data. These functions require PostgreSQL/PostGIS as a spatial database management system, coupled with QGIS and“pgAdmin” (http://www.pgadmin.org/) as front-end clients. Two important pedagogical benefits of PostgresSQL/PostGIS are that (1) they extend QGIS functionality and introduce students to SQL, which has applicability not only here but in many other database situations; and (2) they allowed us to store exercise datasets on a central server in the United States for remote students use, thereby exposing students to the emerging trend of real-time data-services over the net and centralized control of datasets.

In Part III (Table 1) of the course, we introduce students to GIS analysis. Here, we utilize the new QGIS “plug-in” to the GRASS GIS package (also FOSS licensed) that has an extensive set of 
analytic capabilities. One issue we faced is that QGIS-GRASS plug-in works only on data in GRASS format, so any vector or raster data (e.g., shapefiles or ERDAS Imagine images) must be first translated to GRASS format prior to analysis. This is not a limitation though; QGIS-GRASS uses the GDALOGR libraries behind the scenes, to import a variety of data formats into GRASS data, as well as to export any GRASS format results into defacto standard formats (e.g., ESRI shape files, for example, for vector data). The analysis tutorials encourage students first to become familiar with the GRASS data model to help with the use of GRASS-based tools. Then, using a real world site selection problem, the teaching modules explain step by step how to work with raster data - conversion, display, enhancement, raster derived layers production, raster reclassification, clipping, masking, conversion to vector, etc. We also teach the powerful "raster map calculator" function, which can store routines for batch analysis and automatic documentation of the analysis process. Finally, the last analytic modules focus on vector display and analysis operations such as extraction by attributes, feature buffering, or layer intersections. The course concludes with modules and exercises that demonstrated these kinds of functions.

\section{ONLINE DELIVERY METHODS}

The course was delivered online using: (1) Moodle for course management (Moodle.org); (2) a Wiki (Mediawiki.org) for delivery of course tutorials, exercise datasets, and homework assignments; (3) Camtasia (CamtasiaStudio.com) to capture recorded Adobe Flash lectures; (4) Open Office Impress for lecture slides (OpenOffice.org); and (5) Google Gmail for homework submission.

The Moodle site was the primary course entry point. Moodle provides standard features found in online course delivery platforms: page creation, links to internal and remote locations, asynchronous forums that are email based, threaded discussions, and real time chat functions for tri-weekly office hours. We store tutorials on the wiki server for two reasons. First, we wanted an environment where new release updates or translations could be created as part of the OSGeo foundation's higher education 
efforts. Second, the wiki format was the preferred delivery mechanism by the OSGeo education group.

We intended to offer a 3-credit course through the University of Massachusetts online program (https://www.umassulearn.net/), but the enrollment fees for a for-credit course created a dilemma.

Simply put, the standard 3-credit cost to enroll was considerably more than what participants in countries like Nigeria were able to pay, even after attempts by our institution's online program to solve this problem. Given the interest we received (described below) from students in developing countries, we decided to offer it for no-credit and with no fees. Inquiring students embraced this decision.

Course marketing was done via email listservs and through two organizations we have worked with who have colleagues in developing countries (The Center for the Study of Institutions, Population and Environmental Change at Indiana University, CIPEC.org; and The United Nations University International Institute for Software Technology in Macau, China, www.iist.unu.edu). Very quickly we received about 25 queries from interested students. We settled on a group of 18 students, mostly from Nigeria, Uganda, and the United States, but with a one each from Thailand, Brazil and the Maldives.

\section{RESULTS}

The course ran from February to mid-June 2007. However, of the 18 initial participants, only three (two U.S., one Nigerian) completed the full course, two other Nigerians completed three fourths of the course, and two more (1 Nigerian, 1 Ugandan) completed the first half of the course. Given that this may be one of the first higher education online courses delivering content based upon FOSS tools ${ }^{2}$ with specific attention to reaching students in developing countries, it is important to reflect and communicate lessons from this experience.

This section combines post-class reflections from three sources. First, we conducted an online class evaluation survey of participants. Second, we asked co-author Kashwan, a student who completed

2 There are others in the GIS domain. For example, Gary Watry at Florida State University is offering online workshops using FOSS GIS software. See http://www.coaps.fsu.edu/gis/. 
the course and possesses both a U.S. perspective (as a graduate student at another university), and a developing country perspective (India) to provide detailed reactions. Third, we reflected on the experience as course instructors. Given space limitations, we will focus primarily on the question: Why was the completion rate so low? The answer appears to be a combination of three factors: (1) the demanding nature of the course and that it was non-credit; (2) technical issues and software challenges; and, to a lesser extent, (3) the nature of online learning itself. Each are addressed below.

The demanding nature of the course and non-credit. Of the nine students (out of 18) who took the survey, more than half strongly agreed or agreed to our statement that "professional and family issues took away from their time to participate in the course.” A number of other students (two were university professors) who did not take the survey because they dropped out so early told us that they underestimated the time and work required and were too busy with other aspects of their lives. One participant from Uganda put it this way: "The course was interesting, but was not very well suited to a true beginner. Some materials seemed to assume some earlier knowledge. Also, the pace was somewhat fast and quite hard for a beginner to match, which can discourage.”

The fact that the course was offered for no credit - what was first deemed as a positive from the students - turned out to create, for some, a negative incentive. The relatively demanding full-semester course coupled with a non-credit situation led some to fall behind early and eventually give up. The students who responded to the survey (generally ones who completed at least $1 / 3^{\text {rd }}$ of the course) reported that they very much liked the structure and content of the course, although a few commented that it was quite demanding for a non-credit course. Another student from the U.S., who showed interest early but then dropped out, remarked: "I really appreciate that this course was available to so many folks (and for free!) around the world - I feel a little ashamed/guilty of not staying committed to completing the course. For me, it probably would have been beneficial to have invested something in the course to encourage me to participate.” The non-credit disincentive won't be of much surprise to SSCORE readers; these kinds of commitments tend to fall lower on the priority list than others. But 
still this outcome was a surprise to us, given the excitement and appreciation we received from potential students when we initially told them of our decision to offer a free course so they could participate.

Technical issues. Several technical issues contributed to the high drop-out rate, particularly in developing country contexts. First, in the initial weeks accessibility to adequate computers became an issue. One Nigerian fell behind almost immediately because of problems with his computer at work. After a few weeks, he gained access to another computer, but by then he felt too behind to continue.

Second, software installation deterred some students. A few of the African participants ran into difficulties in getting permission to install on their desktop computers at their workplace. For at least one student, his workplace was the only location with both a computer and Internet access, and his organization had strict rules against the installation of non-organizational sanctioned software. Consequently he dropped out. Several other students who had full installation authority on their computer did run into installation problems (not necessarily with QGIS, but with some of the other software required such as Adobe Flash) and required assistance. Our office hour time for the first three weeks of the course was almost completely devoted to solving installation problems. These were tedious sessions using online chat technologies, in part because of all the necessary computer rebooting.

Third, Internet connection and speed was a contributing factor. While only one of the nine students who completed our survey commented that this was a problem, we think that is misleading. Early on in the course, in response to slow network connections, members of the Ugandan cohort requested that we mail CDs containing all the online tutorials, datasets and required software. We did, but it appears we were too late. None of these students made it through the first third of the course, and none have responded to our requests to understand why.

Fourth, software bugs created an added hurdle. Traditionally in the FOSS community a social norm has evolved where users are encouraged or almost expected to report bugs and 
participate as testers. This has evolved from the first generation of FOSS products that were “middleware” products being used by the programmers themselves or highly skilled system administrators. But over the last five years or so, FOSS has moved much farther into the “enduser” software domain, where the users are not technical. In traditional face-to-face teaching environments bugs frustrate students and creates challenges for the instructor. In online teaching situations, where students may feel more isolated, the impact of a bug on the student's patience could be much greater, given they have to deal with this more on their own.

In this class experiment, we ran into difficulties with bugs that were caused either by operating system differences, software versioning differences, or simply because we were teaching with a brandnew release of QGIS. Regarding operating systems, our testing of our QGIS tutorials was limited to the Windows and Linux environments. One of our students was a Mac user and ran into several bugs in the analysis (QGIS-GRASS) tutorials, which eventually led to him to give up on that portion of the course. Other bugs encountered were a product of QGIS version changes. Some of our tutorials were developed using version 0.7 , and we eventually taught with version 0.8 because it included the QGISGRASS plug-in. For some of the 0.7 developed tutorials, we failed to go back and fully test in 0.8. And just our choice of using very new software meant that it would have more bugs than more mature products.

These factors meant students hit some bugs that we did not catch. And here's the main and important problem: in some situations, students working remotely encountered problems where they weren't sure if it was something they weren't doing right, or whether it was really a bug. We tried to remedy this situation by holding regular online office hours in our Moodle chat room, and also trying to be responsive over threaded discussion lists. But even so, brand-new students just learning the tools were facing bug situations which led naturally to some frustrations and discouragement.

Related to this, one of the highly energetic participants from Nigeria remarked: "Students around the world with different network connections and skill sets made support critical but also very 
challenging. I think, given the constraints, it was done quite well, but that is the area that I think would need improving.” He tried to play the role as a "local lead” (for example distributing CDs we sent to others locally) and he suggested that future class offerings might consider the model of identifying a set or network of "local support leads” in various countries to help overcome technical challenges.

Nature of online learning. Finally, returning to the question of why participation was so low, two students (both in the United States) commented that the nature of the online environment itself was challenging. One US participant who dropped out said: “The main issue that kept me from participating through the course was lack of personal contact with teachers or students. Perhaps I need to get better at taking classes online, because I simply did not have the motivation to continue studying/learning.” Another participant who completed the course noted that it was a challenge for him to communicate in a rather "impersonal virtual classroom” environment. He also felt hesitant to ask too many questions because of the free (cost) nature of the course and the impact on instructors' time.

\section{CONCLUSIONS}

Let us conclude with some reflections for two potential types of readers: (1) Instructors interested in learning from other online teaching experiences and with FOSS-based software; and (2) readers interested in efforts to develop “open content” instructional materials that, through licensing, are available over the Internet such as OSGeo.org, MIT Open Courseware (http://ocw.mit.edu/), or Rice University's Connexions (http://cnx.rice.edu/).

For the former group - SSCORE readers who are interested in developing distance learning classes that target developing world students, there are five "lesson” areas we'd like to highlight:

1. Consider the non-credit versus for-credit decision. In our case, based on student survey responses, the no-credit policy appears to have reduced student participation. We also learned that if other instructors in the future offer courses for-credit that target developing country participants, they need to make fees low, or compatible with in-country wages. However, at some underfunded 
universities a no fee or a lower fee policy may be at odds with the strategy of online as a way to bring in needed revenue (Levidow 2002). Instructors need to carefully investigate and consider options well in advance of offering the course. Finally, we also recommend that potential students who take online for-credit offerings at other institutions look carefully, in advance, as to how the credits will be transferred to their home institution. At least one student faced real challenges in this regard.

2. Assess your potential students' Internet connection capabilities and allow ample time for admitted students to get their workstations up and running with course software. Assuming the course is related to desktop-GIS (or desktop software in general), consider mailing CDs with instructional material and software to minimize student time online. Students should check organization software installation policies. This takes weeks to complete and should be done before the class officially starts. 3. Consider your online chat strategy. One benefit of having a relatively small class was that our online chat “office hours” were manageable. If we had the original 18-student enrollment participating in the chats, the sessions would have been difficult to manage. A better strategy might be to use chat (or something like Internet telephony like Skype) for scheduled one or two student support, and encourage more students to use the asynchronous (email) discussions as the main communication platform.

4. Consider a "multiple-pace" course. Some of the students who advanced more rapidly through the course were, in a way, acting as beta-testers of our tutorials for students working at a slower pace. Because of our inability to test on all operating systems they sometimes discovered problems we had not encountered. But the positive of this is that as they encountered these problems, they often solved them and then acted as teaching assistants to students who had not yet done that course component.

5. At an abstract level, think about non-traditional or non-linear forms of pedagogy. Traditional course structures may not fit easily into the more nebulous nature of on-line courses, and attempting to shoe-horn them in may only produce students and professors who feel frustrated and out of sync with the class. In this Introductory GIS class, there is some sequence that is required. But we could have 
offered Part II (database) and Part III (analysis) as modules that could be completed in any order. Alternative models that attempt to move beyond "a syllabus with a course calendar" should be researched and practiced. With the continued growth of on-line courses, it behooves us as educators to come to grips with how this may change the way we should teach.

Now, for the other set of SSCORE readers -- ones who might be interested in collaborative efforts to develop “open content” instructional materials such as OSGeo- we provide several thoughts.

1. Modularity is important. Related to the "non-linear” idea above, given the high-dropout rate we encountered, we think the "OSGeo edu” and other such efforts should be striving to build a library of educational "modules” that can be pieced together to create a full 3-credit FOSS GIS class, but can also serve as online self-study modules. In order to build such a repository, attention needs to be given to prominent listing of authorship which can be cited in an author's Curriculum Vitae.

2. Decisions regarding the platform for tutorial creation and delivery are important before OSGeo proceeds too much farther. Standards should be developed on the structure of tutorials, and there needs to be a decision about the format of these tutorials. The Wiki platform might work, but it differs from the Wikipedia approach in that there should be "locked down” officially sanctioned versions of modules and also “in development” versions of new module releases. Tutorial development should be similar to FOSS software development where there are designated module owners, where there are official releases and then new derivatives go into the pool of content for the next release.

3. All tutorials should encourage the building of a peer-to-peer production system. If free content is to be delivered on OSGeo, for example, there should be a statement in the tutorials that encourages the student to participate in the OSGeo effort, either through software testing, writing documentation or translations, or through assistance to other students. This was emphasized numerous times by one enthusiastic Nigerian participant who is pushing us to create a FOSS GIS "community of practice” where the social network developed could continue beyond the course. An easy way to do this would be to point students to the various OSGeo mailing lists 
(http://lists.osgeo.org/mailman/listinfo).

4. Reaching a balance between the "open content" philosophy for teaching material and the movement toward asset protection at higher institutions? From day-one our intent was to develop course material that would be licensed open content and given back to the community. But this could potentially clash with university intellectual property rights policies (in our case, we never ran into this problem). But upon further reflection, we think there is a middle ground, that is much like what we see in the way companies like Red Hat, IBM, and others work with the FOSS community. We as university instructors provides services "wrapped” around the open content curriculum. Certainly, students could go through the material on their own without any teacher interaction or any credit. But we think the students who participated benefited from our question-response services and our regular weekly interaction. Moreover, if we had offered a class project (as we originally intended, but took out because of the course demands), that exercise would have meant even more interactive services for the students. This idea of "teacher as service provider" aligns itself well with open content higher education efforts like MIT's Open Courseware and Rice University's Connexions or the OSGeo education initiative. In conclusion, despite the low student completion rate of our course, we do not consider this effort a failure. All student communication we had - even ones who dropped out - was extremely positive about the course structure, content and its general idea. And a number of students who dropped out have urged us to offer it again and to maintain the social network established. Finally, one of the students who completed the course said: "not only did I learn GIS, but the course offered the students a nice window to the open source movement. While most students were aware of the FOSS and the efforts at developing open source material, the hands-on exposure that the course offered helped motivate some of the students to think of its potential in expanding educational opportunities across barriers of institutional affiliation and national boundaries. Many of the students are associated with academics in both the developed and developing countries and this course helped ignite ideas for a set of new teaching and training tools that they could potentially employ in their professional 
activities.” From that perspective, this course exceeded our original expectations.

\section{References}

Levidov, L. 2002. Marketizing Higher Education: Neoliberal Strategies and Counter-Strategies. Published in K. Robins and F. Webster, eds, The Virtual University? Knowledge, Markets and Management, pp.227-48. Oxford University Press.

Schweik, C. and English, R. 2007. Schweik, C.M. and English, R. "Conceptualizing the Institutional Designs of Free/Libre and Open Source Software Projects.” First Monday 12(2). Available at http://www.firstmonday.org/issues/issue12_2/schweik/index.html.

Schweik, C., Evans, T. and Grove, J.M. 2005. Open Source and Open Content: a Framework for Global Collaboration in Social-Ecological Research. Ecology and Society 10 (1): 33. [online] URL: http://www.ecologyandsociety.org/vol10/iss1/art33/. 25 pp. 
TABLE 1: INTRODUCTION TO FOSS GEOGRAPHIC INFORMATION SYSTEMS - COURSE OVERVIEW

Part I - Introduction

Week 1: Course preparation. Practice with class communication systems; Installation of required software: Adobe Flashplayer, PDF Creator (for homework submissions), QGIS.

Week 2: Introductory GIS lecture and QGIS exercise and assignment.

Week 3: Lectures on Maps, Space, and Spatial Representation; Assignment: GIS literature review in their field of interest.

Part II - GIS Input Methods

Week 4: Georeferencing concepts lecture; Exercise: GIS Input option 1: Internet data gathering - United States and Global Data.

Week 5: Exercise: GIS Input option 1: An example of regional web resources: Massachusetts, USA digital data; Exercise: Georeferencing with QGIS; Assignment: Searching, downloading and viewing GIS data in QGIS; Assignment:Georeferencing practice.

Week 6: Exercise: On-screen digitizing of features using a scanned map and adding attribute data in QGIS. Assignment: On-screen digitizing practice; Reading: Understanding the Global Positioning System (GPS).

Week 7. GPS field exercise (optional -- for people who have access to a GPS); Exercise: Mapping GPS points after the field with QGIS and adding attribute data (exercise); Lecture: Introduction to relational databases.

Week 8: Relational database theory, Spatial Data Engines (PostGIS/PostgreSQL, PGAdmin); Exercise: Analyzing attribute data with SQL (Part I: Select Statements); Assignment: Computing landuse change using a SQL Select statement; Exercise: Analyzing attribute data with SQL (Part 2: Joining tables).

Week 9. Assignment: Creating a thematic map with QGIS using data from a joined table; Exercise: Installing a PostgreSQL/PostGIS database.

\section{Part III - GIS-Based Analysis}

Week 10. Exercise: Map making in QGIS; Exercise: Analysis using the QGIS GRASS plug-in; Assignment: GRASS plug-in basics.

Week 11. Exercise: Site Selection 1 - Raster Analysis; Exercise: Site Selection 2 - Vector Analysis; Assignment: Raster analysis practice; Assignment: Vector analysis practice.

Note: All exercises are follow CreativeCommons "ShareAlike" license and are available through the OSGEo(http://wiki.osgeo.org/index.php/Educational Resources)

Note

that biographical lines with email contact are missing from the end of the body of the report. 